\title{
Building a Hepatitis C Clinical Program: Strategies to Optimize Outcomes
}

\author{
Autumn Zuckerman, PharmD, BCPS, AAHIVP, CSP ${ }^{1}$ \\ Alicia Carver, PharmD, BCPS, CSP ${ }^{1}$ \\ Cody A. Chastain, $M D^{2, *}$
}

\section{Address}

${ }^{1}$ Specialty Pharmacy Services, Vanderbilt University Medical Center, Nashville, TN, 37232, USA

${ }^{*}, 2$ Division of Infectious Diseases, Vanderbilt University Medical Center, A2200 MCN, 1161 21st Avenue, Nashville, TN, 37232-2605, USA

Email: cody.a.chastain@vumc.org

Published online: 18 0ctober 2018

(C) The Author(s) 2018

This article is part of the Topical Collection on Hepatitis $C$

Keywords Care delivery $\cdot$ Cascade of care $\cdot \mathrm{HCV} \cdot$ Hepatitis C virus $\cdot$ Multidisciplinary care

\begin{abstract}
Purpose of review An increasing number of specialists and non-specialists are developing clinical programs to treat and cure hepatitis $C$ virus (HCV). The goal of this paper is to evaluate and describe optimal strategies to improve outcomes related to HCV care delivery. Recent findings Screening and diagnosis of HCV should be guided by established recommendations. Given the recognized disparity in HCV diagnosis and linkage to care, a multimodal approach involving care coordination and technology resources should be used to improve patient engagement. Access to HCV treatment may be optimized through systematic documentation, prior authorization, and appeal processes. Treatment monitoring should emphasize medication adherence, side effect and drug interaction management, as well as elimination of practical barriers. Finally, post-treatment engagement to promote liver health and reduce the risk of complications or reinfection maximizes the benefit of HCV treatment.

Summary The landscape of HCV treatment has evolved from a specialist-driven model with few patients qualifying for treatment to an opportunity for non-specialists and other providers to provide curative therapies in most patients. Innovative practice models that employ a multidisciplinary approach will likely improve screening, diagnosis, engagement, and treatment outcomes.
\end{abstract}




\section{Introduction}

Direct-acting antiviral (DAA) treatments, with few side effects and high rates of sustained virologic response (SVR), have focused attention on new methods of care delivery to improve outcomes for patients with hepatitis $\mathrm{C}$ virus (HCV) infection. Establishing an HCV clinical program that is focused on optimizing the entire HCV cascade of care is necessary to effectively impact the epidemic and move towards HCV elimination. Outcomes of an HCV clinical program should be defined not only by the number of patients successfully cured but by successes in screening and diagnosis, linkage to care, accessing medications, completion of treatment, appropriate post-treatment monitoring, and reinfection risk reduction. With increasing literature about best practices, clinicians and programs can identify optimal strategies and opportunities to improve each step within this cascade. Here, we review these strategies and provide real-world insights to improve outcomes for the growing number of healthcare providers delivering care to patients with HCV. Table 1 summarizes recommendations to improve clinical practice at each step within HCV care delivery.

\section{Screening and diagnosis}

The first step in the HCV cascade of care is screening and diagnosis. Historically, hepatitis $\mathrm{C}$ screening was recommended for those with specific risk behaviors, risk exposures, or specific medical conditions. These included, but were not limited to, injection drug use (IDU), percutaneous/parenteral exposures in unregulated settings as well as healthcare environments, blood component or organ transplant recipients prior to 1992, HIV infection, and those with unexplained chronic liver disease [1•]. One-time hepatitis $\mathrm{C}$ testing is now recommended by the US Preventative Task Force and Centers for Disease Control and Prevention for persons born between 1945 through 1965 to better identify at-risk persons without relying on risk factor-based screening $[2,3]$. More recently, the American Association for the Study of Liver Diseases (AASLD)/Infectious Diseases Society of America (IDSA) HCV Guidance recommended screening all pregnant women for $\operatorname{HCV}[1 \bullet 4 \bullet]$. These recommendations have evolved to optimally screen the at-risk population and capture those who are actively infected with HCV based on epidemiology trends. Ongoing re-assessment and monitoring of such trends should dictate screening recommendations, especially in light of new therapies that provide high cure rates and can lower population risk of transmission.

Effective HCV screening programs may or may not be co-located with evaluation and treatment programs. As primary care providers (PCPs) or generalists in a variety of settings begin to treat HCV more often, the barrier of linkage to care (LTC) may be significantly decreased for some populations $[5,6 \bullet]$. While this model may improve LTC, it may not be feasible in certain regions. HCV clinical programs that do not regularly care for patients prior to diagnosis may disseminate recommendations regarding HCV screening to potential community or healthcare partners along with information to help facilitate effective LTC. Promoting knowledge and screening within the community may enhance the visibility and efficacy of such HCV clinical programs. 


\section{Linkage and access to care}

Following diagnosis of active HCV, all patients should be linked to a practitioner able to provide comprehensive HCV management including liver disease severity assessment and HCV treatment [1•]. Patients with advanced fibrosis (Metavir stage $\geq 3$ ) may benefit from consultation with a hepatologist for ongoing advanced fibrosis care to ensure appropriate hepatic health monitoring and screening, and to evaluate for possible liver transplant eligibility [ $1 \bullet]$.

Improving outcomes for patients with HCV involves creating convenient, accessible, and multidisciplinary methods of care delivery. A number of studies have shown significant divergence between diagnosis and LTC $[7-9,10 \bullet]$. This breakdown in the cascade of care has become more pronounced with increasing HCV infection among those with active IDU. People who inject drugs (PWID) often face social stigma and unique health system barriers that result in poor HCV care engagement [11]. In one study of 861 suburban heroin users aged 1735 years in New Jersey, 237 had a positive HCV antibody on screening, but only $16(6.8 \%)$ patients attended an in-office visit, and only $3(1.3 \%)$ initiated DAA therapy. [12]

Dedicating resources for support staff to address LTC, such as a LTC specialist (LTCS) or patient navigator, has shown encouraging results. In one study of methadone clinics, sober living homes, and drug rehabilitation centers, integrating a LTCS resulted in nearly a third $(n=116,29.1 \%)$ of HCV patients attending an initial clinic visit [13]. Use of a patient portal for education and appointment information also served to enhance patient experience and engagement in this program [13]. Within a Baltimore sexually transmitted infection (STI) clinic, utilization of a LTC coordinator led to 52\% $(n=81)$ of HCVpositive individuals attending an offsite HCV specialist appointment [14]. From these and other LTC studies, it is clear that identification and designation of resources to facilitate LTC from the time of diagnosis can improve the rate at which those with diagnosed HCV complete medical evaluations [11, 15, 16].

In the past, $\mathrm{HCV}$ treatment often required referral to a specialist for treatment as well as close monitoring of dose-limiting adverse effects [17•]. In the DAA era, therapy that is safe, effective, and requires minimal monitoring can be delivered effectively by non-specialists and other providers with comparable outcomes $[6 \bullet 18,19]$. Co-localizing HCV treatment in settings in which patients are already engaged in care (such as primary care clinics, substance abuse treatment centers, and methadone maintenance facilities) can overcome access barriers for patients unwilling or unable to seek specialty care [20, 21, $22 \bullet \bullet]$. In addition to task shifting, there has been increased emphasis on HCV treatment delivered by PCPs [23]. PCPs are often the first line of patient engagement into the healthcare system and are the most likely specialist to have the opportunity to screen patients for HCV [24]. However, a survey of 80 PCPs found that the majority (70\%) did not feel up to date on current HCV treatment options and most severely underestimated the efficacy of DAA regimens [25]. Additionally, one claims-based study from 2010 to 2016 found that only $13.3 \%$ of patients with a positive HCV antibody screened by a PCP received treatment [24]. Patients were even less likely to receive treatment if screened by an obstetrician-gynecologist (OBGYN) compared to a PCP (OR 0.493, 95\% 


\section{Treatment access}

Wald Confidence Limits $0.353-0.688$ ), with only $4.7 \%$ of patients screened by an OBGYN receiving treatment [24].

These findings underline the importance of educating PCPs and non-HCV specialists that are more likely to encounter undiagnosed and untreated patients on the benefits of treatment and treatment algorithms. While task shifting has become a viable option for HCV care delivery, available evidence to support this model consistently involves education of providers that will be implementing new HCV clinical programs $[6 \bullet, 19]$. There are a number of educational resources for providers including the comprehensive University of Washington and University of Alabama at Birmingham "Hepatitis C Online" training course funded by a grant from the Centers for Disease Control and Prevention as well as a variety of other sources (Table 2) [26].

Finally, the use of telehealth technologies to engage patients in care offers promising solutions for a growing population of rural patients. Telehealth programs range from educational and consultative resources such as Project ECHO (Extension for Community Healthcare Outcomes), to specialist and non-specialist patient-facing clinics $[27,28,29 \bullet \bullet, 30,31]$. Coverage of telehealth services varies by insurance provider and by state but is increasingly reimbursed [32]. Depending on how these services are provided, telehealth limitations may include lower-quality physical assessment, limited laboratory and imaging availability, and lower quality patient-provider relationship [32]. However, incorporating telehealth services, including video calls, telephone calls, and online platforms, will likely increase patient access to treatment and improve engagement in care in future practice.

Expanding patient access to HCV therapies is essential in achieving improved patient outcomes. Many public and private insurers initially responded to the high costs of HCV medications by placing restrictions on patient eligibility, such as requiring documentation of advanced liver fibrosis, maintaining a period of abstinence from substance use, and limiting the type of prescriber to gastroenterology or infectious disease specialists [33•, 34-36]. This pattern was reflected by a recent large pharmacy network study, demonstrating an overall HCV therapy start rate of only $70 \%$ in 2016 , with failure to start primarily driven by insurance denials (83\%) [34]. Lo Re and colleagues identified the most common reasons for absolute denial of therapies were insufficient information to assess medical need (36\%) and lack of medical necessity (35\%) [37•]. These data suggest that current processes in applying for treatment through pharmacy benefits managers (PBMs) are challenging and demonstrate the opportunity for improvements in navigating the approval process.

Multidisciplinary models have implemented a variety of strategies, including patient navigators, nurses, social workers, and specialty pharmacies, to overcome barriers and improve patient access [15, 38, 39]. Patient approval rates utilizing a program nurse alongside a patient navigator were $93 \%$ as compared to $81-91 \%$ demonstrated in several real-world studies [39, 40, 41•, 42]. Other examples of successful models integrate specialty pharmacies directly into the HCV multidisciplinary team; these models have improved medication approval and access rates while decreasing time to therapy initiation and 


\section{Table 1. Recommendations to improve outcomes when establishing an HCV practice}

\begin{tabular}{|c|c|c|}
\hline $\begin{array}{l}\text { Practice } \\
\text { element }\end{array}$ & Recommendation & Brief description \\
\hline \multirow[t]{2}{*}{$\begin{array}{l}\text { Screening and } \\
\text { diagnosis }\end{array}$} & $\begin{array}{l}\text { Guideline-recommended } \\
\text { screening }\end{array}$ & $\begin{array}{l}\text { All clients with known risk behaviors, risk exposures, or other pertinent } \\
\text { medical conditions should be screened for HCV. }\end{array}$ \\
\hline & Public health awareness & $\begin{array}{l}\text { HCV clinical programs should promote community awareness of HCV and } \\
\text { appropriate screening indications. }\end{array}$ \\
\hline \multirow[t]{3}{*}{$\begin{array}{l}\text { Linkage and } \\
\text { access to } \\
\text { care }\end{array}$} & $\begin{array}{l}\text { Patient navigation } \\
\text { program }\end{array}$ & $\begin{array}{l}\text { Following a diagnosis of HCV, staff contacts patients for education and } \\
\text { appointment scheduling. Specialists/patient navigators should monitor } \\
\text { patients to ensure appointment attendance and follow-up by phone, in } \\
\text { person, or other technology (app, portal, text, etc.) to engage those who } \\
\text { miss an appointment. }\end{array}$ \\
\hline & Telehealth & $\begin{array}{l}\text { HCV providers utilize telecommunications such as an electronic portal, video } \\
\text { conferencing, and telephone calls to engage patients in care beyond a } \\
\text { clinic visit. }\end{array}$ \\
\hline & Non-specialist care & $\begin{array}{l}\text { Physicians, nurse practitioners, physician assistants, or pharmacists provide } \\
\text { HCV evaluation and treatment exclusive of a gastroenterologist, } \\
\text { hepatologist, or infectious diseases provider. Thorough education and } \\
\text { training should be completed prior to prescribing HCV treatment. }\end{array}$ \\
\hline \multirow[t]{2}{*}{$\begin{array}{l}\text { Treatment } \\
\text { access }\end{array}$} & $\begin{array}{l}\text { Patient navigation } \\
\text { program }\end{array}$ & $\begin{array}{l}\text { Specialists/patient navigators should work closely with the patient and } \\
\text { pharmacy to ensure all steps for medication approval are followed } \\
\text { appropriately and to completion. }\end{array}$ \\
\hline & Cost management & $\begin{array}{l}\text { High out-of-pocket patient costs should be defrayed by specialist/patient } \\
\text { navigator prior to therapy initiation. }\end{array}$ \\
\hline \multirow[t]{4}{*}{$\begin{array}{l}\text { Treatment } \\
\text { monitoring }\end{array}$} & $\begin{array}{l}\text { Patient navigation } \\
\text { program }\end{array}$ & $\begin{array}{l}\text { Specialists/patient navigators should work closely with the patient and } \\
\text { pharmacy to ensure continued treatment access and appropriate follow-up. } \\
\text { Linkage to additional support (i.e., mental health professional, social work) } \\
\text { may be necessary to overcome barriers to treatment completion. }\end{array}$ \\
\hline & $\begin{array}{l}\text { Guideline-recommended } \\
\text { monitoring }\end{array}$ & $\begin{array}{l}\text { Patients should be monitored according to the AASLD/IDSA treatment } \\
\text { guidance, focusing on continued assessment of adherence, drug-drug } \\
\text { interactions, and adverse events while on treatment. }\end{array}$ \\
\hline & Non-specialist care & $\begin{array}{l}\text { Non-specialist providers provide HCV treatment monitoring. Thorough } \\
\text { education and training of non-specialists should be completed prior to } \\
\text { prescribing HCV treatment. }\end{array}$ \\
\hline & Telehealth & $\begin{array}{l}\text { HCV providers utilize telecommunications such as an electronic portal, video } \\
\text { conferencing, and telephone calls to monitor patients while on treatment. }\end{array}$ \\
\hline \multirow[t]{2}{*}{$\begin{array}{l}\text { Post-treatment } \\
\text { engagement }\end{array}$} & Patient education & $\begin{array}{l}\text { All patients should be educated regarding the clinical implications for SVR, } \\
\text { the risk of reinfection, and the need for further liver care depending on } \\
\text { fibrosis status. }\end{array}$ \\
\hline & $\begin{array}{l}\text { Advanced liver disease } \\
\text { care }\end{array}$ & $\begin{array}{l}\text { All patients with advanced fibrosis should be linked to for liver disease care } \\
\text { including hepatocellular carcinoma and esophageal varices screening. }\end{array}$ \\
\hline
\end{tabular}


Table 2. Practice resources

\begin{tabular}{|c|c|c|}
\hline $\begin{array}{l}\text { Practice } \\
\text { element }\end{array}$ & Resource & Description \\
\hline \multirow[t]{5}{*}{ Provider support } & $\begin{array}{l}\text { Hepatitis C online course: https://www. } \\
\text { hepatitisc.uw.edu/ }\end{array}$ & $\begin{array}{l}\text { Comprehensive course including HCV disease state, treatment, } \\
\text { and provider resources (e.g., calculators, clinical trial } \\
\text { information, landmark study reviews). }\end{array}$ \\
\hline & $\begin{array}{l}\text { Fundamentals of liver disease: https://www. } \\
\text { aasld.org/research-awards/fundamentals- } \\
\text { liver-disease }\end{array}$ & $\begin{array}{l}\text { CME module for physicians encompassing viral hepatitis } \\
\text { training. This is a collaborative effort of American } \\
\text { Association for the Study of Liver Disease, ECHO, the } \\
\text { American College of Physicians, CDC, and the Department } \\
\text { of Veterans Affairs. }\end{array}$ \\
\hline & $\begin{array}{l}\text { American Liver Foundation Provider Locator: } \\
\text { https://hepc.liverfoundation.org/find-a- } \\
\text { healthcare-provider/ }\end{array}$ & $\begin{array}{l}\text { Patients can locate treating providers by location and } \\
\text { specialty. }\end{array}$ \\
\hline & $\begin{array}{l}\text { HEP Drug Interactions: https://www.hep- } \\
\text { druginteractions.org/ }\end{array}$ & An up-to-date, evidence-based drug-drug interaction resource. \\
\hline & $\begin{array}{l}\text { Clinician Consultation Center: http://nccc.ucsf. } \\
\text { edu/clinician-consultation/hepatitis-c- } \\
\text { management/ }\end{array}$ & $\begin{array}{l}\text { Consultative service through the University of California, San } \\
\text { Francisco, for providers managing patients with HCV and } \\
\text { co-morbidities such as HIV or substance use. Assists with } \\
\text { appropriate HCV therapy selection and issues regarding } \\
\text { treatment. }\end{array}$ \\
\hline $\begin{array}{l}\text { Screening and } \\
\text { diagnosis }\end{array}$ & $\begin{array}{l}\text { CDC provider and patient information: } \\
\text { https://www.cdc.gov/hepatitis/hcv/index.htm }\end{array}$ & $\begin{array}{l}\text { Provider and patient fact sheets to increase awareness, } \\
\text { appropriate screening, and diagnosis practice. }\end{array}$ \\
\hline \multirow[t]{8}{*}{ Treatment access } & $\begin{array}{l}\text { National viral hepatitis roundtable: } \\
\text { http://nvhr.org/content/provider-resources }\end{array}$ & $\begin{array}{l}\text { Broad coalition providing resources for navigating prior } \\
\text { authorization, sample appeal templates, and best practices } \\
\text { for HCV treatment assessment and monitoring. }\end{array}$ \\
\hline & $\begin{array}{l}\text { HCV treatment access: } \\
\text { http://hcvtreatmentaccess.org }\end{array}$ & $\begin{array}{l}\text { Resources to help providers improve access to HCV } \\
\text { medications, including sample appeal templates, links } \\
\text { to patient assistance programs, and clinical resources. }\end{array}$ \\
\hline & $\begin{array}{l}\text { Patient Access Network Foundation (PANF): } \\
\text { https://panfoundation.org }\end{array}$ & $\begin{array}{l}\text { Patient assistance for HCV patients with high deductibles } \\
\text { and co-pays. }\end{array}$ \\
\hline & $\begin{array}{l}\text { Patient Advocate Foundation (PAF): } \\
\text { http://www.patientadvocate.org }\end{array}$ & $\begin{array}{l}\text { Patient assistance for HCV patients with high deductibles and } \\
\text { co-pays. }\end{array}$ \\
\hline & $\begin{array}{l}\text { HealthWell Foundation: } \\
\text { https://www.healthwellfoundation.org/ }\end{array}$ & $\begin{array}{l}\text { Patient assistance for HCV patients with high deductibles and } \\
\text { co-pays. }\end{array}$ \\
\hline & $\begin{array}{l}\text { The Assistance Fund (TAF): } \\
\text { https://tafcares.org/ }\end{array}$ & $\begin{array}{l}\text { Patient assistance for HCV patients with high deductibles and } \\
\text { co-pays. }\end{array}$ \\
\hline & Good Days: https://www.mygooddays.org/ & $\begin{array}{l}\text { Patient assistance for HCV patients with high deductibles and } \\
\text { co-pays. }\end{array}$ \\
\hline & Industry resources & $\begin{array}{l}\text { DAA manufacturers provide co-pay cards to reduce patient } \\
\text { cost after insurance approval. Only patients with } \\
\text { non-federal insurance plans qualify for these programs. } \\
\text { Co-pay cards may be found on the manufacturer website. }\end{array}$ \\
\hline
\end{tabular}

CME Continuing Medical Education, HCV Hepatitis C virus, ECHO Extension for Community Healthcare Outcomes, CDC Centers for Disease Control and Prevention 
reducing patient financial burden $[43,44]$. Specialty pharmacy integration may include embedding a trained pharmacy technician or pharmacist in an affiliated clinic to work independently or alongside a nurse coordinator [43, 44]. When this type of integration is not an option, developing and maintaining a strong relationship with an external or internal specialty pharmacy may provide similar patient access successes [45].

Regardless of the type of model utilized, a knowledgeable, devoted team skilled in navigating the authorization process is critical to patient access. This process typically begins with a benefits investigation (BI) for insured patients, followed by a prior authorization (PA) request and possible appeals, and ends with financial assistance applied to insured patients' costs. During the BI, determining and utilizing the PBM-preferred pharmacy, as well as an appropriate preferred treatment regimen, reduces unnecessary denials and delays in treatment initiation. When completing a PA request, it is important to provide all requested clinical information and documentation in order to prevent otherwise unnecessary denials. If all the requested information is not available, it is essential to communicate with and assist the patient in obtaining this information prior to PA submission. In the case of an initial PA denial, it is necessary to determine next steps, such as an appeal or peer-to-peer review. During the appeal or peer-to-peer review, it is recommended to provide supporting documentation as well as evidence for clinical necessity utilizing evidence-based literature to support the request.

Resources are available for clinicians and staff to assist with this process including sample appeal templates [46, 47]. If the regimen is denied after exhausting all options for insurance approval, an application for patient assistance through the respective manufacturer may be pursued.

In addition to the insurance restrictions and the approval process, other patient access barriers remain, such as lack of insurance or high out-of-pocket patient costs after PBM approval. Those underinsured and without insurance should pursue assistance through the respective manufacturer, as outlined previously for those with absolute insurance denials. For those patients not participating in state or federally funded insurance programs, manufacturer copay cards may be obtained to defray high copay costs. Alternatively, for those patients enrolled in state or federally funded insurance programs, patient foundations exist (i.e., Patient Access Network Foundation, Patient Advocate Foundation, The Assistance Fund, Good Days, and HealthWell Foundation) for qualifying patients with unaffordable copay costs (Table 2).

\section{Treatment monitoring}

Despite improved safety and efficacy of HCV therapies, on-treatment monitoring remains an important part of the cascade of care. Treatment monitoring in the DAA era includes ensuring adherence through therapy completion, identifying and mitigating drug interactions and adverse effects, and assessment of appropriate response to therapy $[48 \bullet$.

The patient navigator, nurse coordinator, and or specialty pharmacy should remain involved in the monitoring phase in order to ensure continuous patient access to treatment, especially during transitions of care (i.e., from outpatient to inpatient). Following initial approval of HCV medication, approval terms (including approval dates and any on-treatment laboratory requirements) should be 
reviewed and addressed if needed in order to avoid any potential lapses in treatment. Additional prior authorizations required throughout treatment should also be quickly completed, if applicable.

Once DAA therapy is initiated, it is important to systematically assess medication adherence, potential drug-drug interactions utilizing appropriate resources (such as prescribing information and the University of Liverpool Hep Drug Interactions tool), treatment response utilizing laboratory data, and potential adverse events [49•]. Patients should be monitored as per the AASLD/IDSA HCV Guidance recommendations [48 $\bullet$. It is currently recommended for patients to be assessed for initial treatment response approximately 4 weeks into treatment, as positive viremia at this time indicates the need for reassessment of adherence, possible drugdrug interactions, and additional testing to ensure an undetectable viral load while on treatment [48•]. Patient safety should also be assessed while on treatment, particularly among those treated with ribavirin-containing regimens, decompensated patients, and those at risk for hepatitis B virus reactivation.

Successful and effective monitoring can be achieved utilizing different models. As previously mentioned, due to the improved safety and efficacy of DAAs, non-specialist providers can effectively treat and monitor HCV patients with comparable outcomes following thorough education and training $[6 \bullet, 18]$. Utilization of non-physician providers could also potentially improve patient adherence to on-treatment visits, as suggested by one study in which treatment visit adherence was higher in those patients seen by a nurse practitioner $(73.6 \%$ [CI, 69.4 to $77.9 \%]$ ), as compared to a specialist (55.9\% [CI 52.6 to $59.3 \%$ ]) [6•]. Notably, those patients that achieved SVR demonstrated higher adherence to treatment visits as well (65.8 vs. $40.5 \%)$ [6•].

Pharmacists may also contribute directly to therapy monitoring either in clinic or via telemedicine. Studies have demonstrated improved adherence in addition to preventing drug-drug interactions and medication errors with pharmacy involvement [50-53]. More than $50 \%$ of $\mathrm{HCV}$ patients treated in a multidisciplinary model consisting of an infectious diseases physician, HCV nurse, and specialty pharmacist were identified to have drug-drug interactions requiring interventions by a pharmacist [50]. Initial treatment education and follow up monitoring every 4 weeks were completed by the HCV nurse and pharmacist, as well as one on-treatment office visit with the provider [50]. Utilizing this model, no patients stopped treatment due to adverse effects and $79.1 \%$ of patients reported $100 \%$ adherence rates [50].

Telemedicine has the potential to improve adherence in patients on treatment as well, particularly among those with limited provider access. Although there is limited data available on those patients treated with DAAs, studies have demonstrated similar SVR rates for those telemedicine and non-telemedicine patients treated with DAAs as well as pegylated interferon and ribavirin [5456]. Additionally, adverse drug events were more likely to cause nontelemedicine patients to discontinue treatment than those telemedicine patients receiving the same treatment $[5,55]$.

It is important to recognize that patients infected with HCV often have social and psychological barriers to adherence and treatment completion and may require additional support [11]. Some models incorporate mental health professionals and social work into clinical programs, resulting in high HCV treatment completion rates [57]. Strategies to assist patients with complex needs have been described by Sublette et al., including patient advocacy (i.e., housing and income 
stability during treatment), practical problem solving to help patients adhere, ongoing feedback to provide positive reinforcement, and emotion-focused support to assess psychological impact of treatment and improve mood [58]. Another study more specifically addressed adherence and outcomes by utilizing direct observation of DAA in PWID receiving opioid agonist therapy under direct observation by a nurse or physician. This direct-observation model resulted in high adherence, with 1875 of 1878 scheduled DAA doses ingested, as well as high SVR rates $(n=40$; $100 \%$ ), demonstrating that previously difficult-to-treat patients can have successful outcomes [59•].

\section{Post-treatment engagement}

Continued patient engagement in medical care beyond completion of DAA therapy is essential for effective HCV clinical programs. All patients who complete DAA therapy should be evaluated for SVR at least 12 weeks after completing therapy to confirm clinical response and to determine the plan for subsequent liver care [48•].

For those who do not achieve SVR, ongoing disease assessment should occur every 6-12 months and, if appropriate, cirrhosis care including hepatocellular carcinoma monitoring. Recommendations for retreatment after DAA failure with new DAA agents are available, and HCV clinical programs should be prepared for a small number of patients to relapse despite appropriate treatment and treatment adherence [60•]. As multiple DAA therapy options are now recommended by the Food and Drug Administration for retreatment after DAA failure, retreatment strategies have become more feasible for clinical programs.

For those who achieve SVR after DAA treatment, the need for ongoing medical care is determined by the degree of liver fibrosis present. Patients who do not have advanced fibrosis and who achieve SVR do not require further liver care and monitoring; these patients may follow-up "as if they were never infected with HCV" as per the AASLD/IDSA guidance. Patients who achieve SVR but have cirrhosis need ongoing liver care including hepatocellular carcinoma monitoring at appropriate intervals as well as baseline endoscopy as part of the HCV clinical program or after referral for further care [48•].

All patients who achieve SVR require counseling. These patients should be aware that screening tests based on HCV antibodies will remain positive lifelong despite SVR. Patients who achieve SVR should be educated that engaging in highrisk behaviors may result in HCV reinfection. Reinfection rates have varied greatly across cohorts depending on risk behaviors observed [61•, 62-64]. High-risk groups, including PWID, men who have sex with men, and those with HIV/HCV coinfection, should receive specific education including risk reduction strategies. HCV clinical programs should be able to provide HCV reinfection screening for patients who remain at risk or educate patients regarding screening resources available in their community. Vanderbilt University Medical Center (VUMC) offers a singular example of practices to improve clinical outcomes. Patients referred to VUMC for HCV care are treated either through the Division of Gastroenterology, Hepatology, and 
Nutrition (GI) or through the Division of Infectious Diseases (ID). Within both of these clinics, specialty pharmacist(s) are embedded that serve as medication experts but also effectively as patient care coordinators, ensuring that patients are able to efficiently navigate from an initial visit to the anticipated clinical outcome of SVR. This process is detailed in Fig. 1.

Multidisciplinary care begins with a patient's initial visit to one of the VUMC outpatient clinics. Following a disease assessment by a prescribing provider (physician, physician's assistant, or advanced practice nurse practitioner), the patient is contacted by a pharmacist either within the same clinic visit (ID) or by phone subsequently (GI). The pharmacist counsels the patient on the process of obtaining treatment and provides preliminary medication education. The pharmacist ensures necessary laboratory, staging, and supplemental insurance requirements (e.g., resistance testing, rehabilitation certificates, adherence assessments) are completed either at the initial visit or as early as possible. A comprehensive medication reconciliation is performed and any possible drug interactions with DAA therapy are addressed. This early relationship between patient and pharmacist provides patients an accessible care coordinator, reducing patients' risk for being lost to follow-up after an initial visit. For other practices unable to integrate clinical pharmacists, prescribing providers could address potential drugdrug interactions, and clinic staff such as nurse coordinators, social workers, or case managers could play the vital role of educating patients regarding treatment access and ensuring appropriate work-up completion.
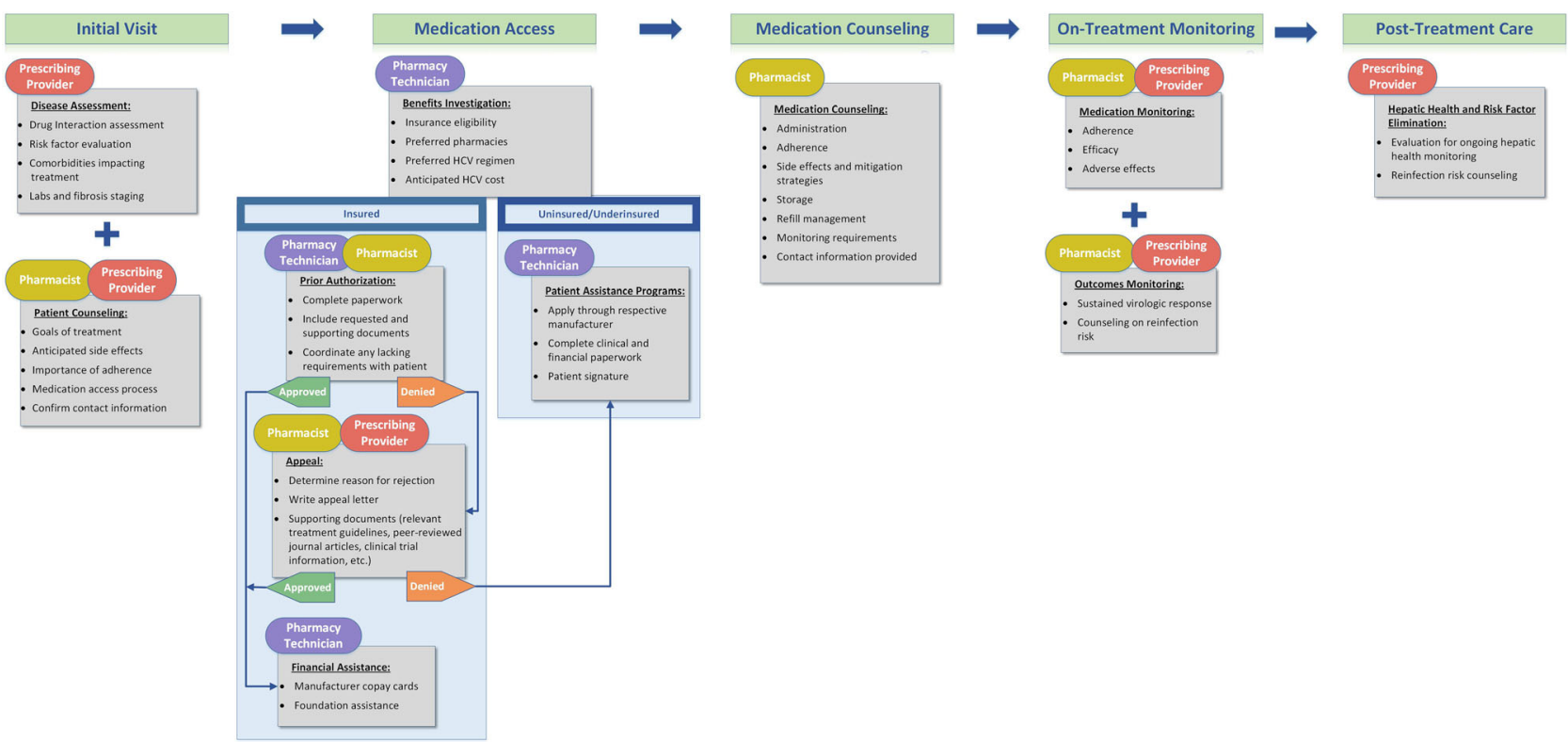

Fig. 1. Vanderbilt University Medical Center Division of Gastroenterology, Hepatology, and Nutrition and Division of Infectious Diseases employ a multidisciplinary approach in hepatitis $C$ care delivery that integrates a prescribing provider (physician, nurse practitioner, or physician's assistant), a pharmacist, and a pharmacy technician into clinical practice. The figure describes the cascade of care and corresponding responsibilities from an initial clinic visit through treatment completion and sustained virologic response. 
Within the VUMC model, the most appropriate treatment is collaboratively agreed upon by the pharmacist and prescribing provider after completion of disease state assessment. Coordinating medication access is a key role of both the integrated pharmacist(s) and pharmacy technician (Fig. 1). The integrated model of care is advantageous as it allows pharmacists full access to necessary medical information that is required for treatment access document completion. Additionally, forms requiring a patient signature can be easily completed at an initial visit if the pharmacist identifies insurance-specific or patient assistance program (PAP) requirements. Pharmacists and technicians complete PAs and appeals as necessary for patients with insurance. When patients are denied treatment after multiple appeals (underinsured), the pharmacist attempts to obtain treatment through manufacturer programs. Within the ID clinic over 14 months, this model resulted in a $96 \%$ medication access rate, with only $3 \%$ of people denied treatment, all with Medicaid insurance [53]. Again, in clinical programs where these integrated pharmacy services are not available, developing a partnership with a specialty pharmacy that frequently assists with DAA treatment may be helpful. Upon practice establishment, providers should recognize specific clinic staff (e.g., nurses, technicians) that specialize in helping patients access treatment and can become familiar with the process and the requirements.

Following treatment approval, pharmacists educate patients on the importance of adherence to therapy, what to expect while on therapy, and necessary monitoring on and after treatment. Patients receive direct contact information to facilitate treatment adherence if troublesome side effects and/or other concerns arise. This role is best fulfilled by a pharmacist, though if a pharmacist is not integrated into a clinical program or able to document patient understanding in the electronic medical record, clinic staff should confirm patients' understanding of the medication education provided by the dispensing pharmacy.

At clinic follow-up visits, prescribing providers complete necessary lab monitoring and provide further counseling on treatment plans and post-treatment requirements. In the interim, pharmacists monitor patient side effects, adherence, and for any possible lapses in therapy due to hospitalization, incarceration, or other situations that may arise. The pharmacy technician calls patients 7-10 days prior to completion of their first month of therapy to ensure timely medication delivery and clinic follow-up. These roles could be fulfilled by nursing coordinators or others for clinical programs without integrated pharmacy staff.

Once treatment is completed, patients are assessed for an SVR at least 12 weeks following treatment completion. If an SVR is achieved, the prescribing provider will discuss the need for ongoing liver care and hepatocellular carcinoma monitoring and counsel patients regarding future care as described above. In the infrequent instance when a cure was not achieved, patients are evaluated for further treatment.

Within this model of care, over 1500 patients have been treated and cured of $\mathrm{HCV}$ over the last 5 years. The successful outcomes of this model are due in part to a multidisciplinary team focused on patient engagement, education, and empowerment. 


\section{Conclusion}

The impact of HCV therapy on population health hinges on increasing screening and treatment as well as reducing HCV exposure risk. Successful strategies to identify and treat patients with HCV should include frontline providers such as PCPs, and clinical programs should employ a multidisciplinary approach to effectively engage and retain patients through treatment completion. Finally, ensuring response to treatment and advocating post-treatment monitoring as well as HCV risk reduction is essential to promote optimal HCV treatment outcomes. With effective HCV treatment now the standard of care, ongoing research should focus on improving identification of patients with active infection, best practices in delivering HCV care, and innovative strategies to reduce and eliminate the spread of HCV.

\section{Compliance with ethical standards}

\section{Conflict of interest}

Dr. Alicia Carver has no financial or ethical disclosures. Dr. Cody Chastain receives grant/research support from Gilead Sciences, Inc. Dr. Autumn Zuckerman receives grant/research support from Gilead Sciences, Inc.

\section{Human and animal rights}

This article does not contain any studies with human or animal subjects performed by any of the authors.

Open Access This article is distributed under the terms of the Creative Commons Attribution 4.0 International License (http://creativecommons.org/licenses/by/4.0/), which permits unrestricted use, distribution, and reproduction in any medium, provided you give appropriate credit to the original author(s) and the source, provide a link to the Creative Commons license, and indicate if changes were made.

\section{References and Recommended Reading}

Papers of particular interest, published recently, have been highlighted as:

- Of importance

-. Of major importance

1. $\quad$ AASLD-IDSA. HCV Testing and Linkage to Care. 2017. https://www.hcvguidelines.org/evaluate/testing-andlinkage. Accessed June 22018.

The AASLD-IDSA HCV guidance provides recommendations for testing, managing, and treating HCV and is regularly reviewed and updated. This section discusses screening for $\mathrm{HCV}$ and appropriate linkage to care.

2. Moyer VA, Force USPST. Screening for hepatitis C virus infection in adults: U.S. preventive services task force recommendation statement. Ann Intern Med.
2013;159(5):349-57. https://doi.org/10.7326/00034819-159-5-201309030-00672.

3. Smith BD, Morgan RL, Beckett GA, Falck-Ytter Y, Holtzman D, Teo C-G et al. Recommendations for the identification of chronic hepatitis $\mathrm{C}$ virus among persons born during 1945-1965. Morbidity and Mortality Weekly Report: Centers for Disease Control and Prevention; 2012.

4. $\quad$ AASLD-IDSA. HCV in pregnancy. In: Recommendations for testing, managing, and treating hepatitis C. 
https://www.hcvguidelines.org/unique-populations/ pregnancy. Accessed June 2018.

The AASLD-IDSA HCV guidance provides recommendations for testing, managing, and treating HCV and is regularly reviewed and updated. This section discusses appropraite management and testing of HCV in pregnancy.

5. Arora S, Thornton K, Murata G, Deming P, Kalishman $\mathrm{S}$, Dion D, et al. Outcomes of treatment for hepatitis C virus infection by primary care providers. N Engl J Med. 2011;364(23):2199-207. https://doi.org/10.1056/ NEJMoa1009370.

6. Kattakuzhy S, Gross C, Emmanuel B, Teferi G, Jenkins V, Silk R, et al. Expansion of treatment for hepatitis C virus infection by task shifting to community-based nonspecialist providers: a nonrandomized clinical trial. Ann Intern Med. 2017;167(5):311-8. https://doi. org/10.7326/M17-0118

This nonrandomized, open-label multi-site clinical trial is the largest in the DAA era to demonstrate in a real-world cohort that HCV treatment provided by nonspecialist resulted in similar safety and efficacy as treatment provided by specialists.

7. Dever JB, Ducom JH, Ma A, Nguyen J, Liu L, Herrin A, et al. Engagement in care of high-risk hepatitis C patients with interferon-free direct-acting antiviral therapies. Dig Dis Sci. 2017;62(6):1472-9. https://doi. org/10.1007/s10620-017-4548-4.

8. Bourgi K, Brar I, Baker-Genaw K. Health disparities in hepatitis $\mathrm{C}$ screening and linkage to care at an integrated health system in Southeast Michigan. PLoS One. 2016;11(8):e0161241. https://doi.org/10.1371/ journal.pone.0161241.

9. Machado SM, Almeida C, Pinho JRR, Malta FM, Capuani L, Campos AF, et al. Hepatitis C among blood donors: cascade of care and predictors of loss to followup. Rev Saude Publica. 2017;51(0):40. https://doi.org/ 10.1590/S1518-8787.2017051006468.

10. Jonas MC, Rodriguez CV, Redd J, Sloane DA, Winston BJ, Loftus BC. Streamlining screening to treatment: the hepatitis $\mathrm{C}$ cascade of care at Kaiser permanente midAtlantic states. Clin Infect Dis. 2016;62(10):1290-6. https://doi.org/10.1093/cid/ciw086

The authors report the design, implementation, and preliminary results of an algorithm to screen and link patients to care. This detailed explanation of a best practice to improve HCV care engagement following screening may be useful in guiding future care delivery models.

11. Bajis S, Dore GJ, Hajarizadeh B, Cunningham EB, Maher L, Grebely J. Interventions to enhance testing, linkage to care and treatment uptake for hepatitis C virus infection among people who inject drugs: a systematic review. Int J Drug Policy. 2017;47:34-46. https://doi.org/10.1016/j.drugpo.2017.07.002.

12. Akyar E, Seneca KH, Akyar S, Schofield N, Schwartz MP, Nahass RG. Linkage to care for suburban heroin users with hepatitis $C$ virus infection, New Jersey, USA. Emerg Infect Dis. 2016;22(5):907-9. https://doi.org/10.3201/ eid2205.151980.
13. Alam TZBH, Cook D, Kausar L, Alam I, editor. HCV testing and linkage to care: expanding access to $\mathrm{HCV}$ care through electronic health engagement. EASL; 2018 Apr 11-15; Paris, France.

14. Falade-Nwulia O, McAdams-Mahmoud A, Irvin R, Niculescu A, Page KR, Mix M et al. Primary care providers knowledge, attitude and practices related to hepatitis $\mathrm{C}$ screening and treatment in the oral direct acting antiviral agents era. J Community Med Health Educ 2016;6(5). https://doi.org/10.4172/2161-0711.1000481.

15. Ford MM, Johnson N, Desai P, Rude E, Laraque F. From care to cure: demonstrating a model of clinical patient navigation for hepatitis $\mathrm{C}$ care and treatment in high-need patients. Clin Infect Dis. 2017;64(5):685-91. https://doi.org/10.1093/cid/ ciw806.

16. Sena AC, Willis SJ, Hilton A, Anderson A, Wohl DA, Hurt $\mathrm{CB}$, et al. Efforts at the frontlines: implementing a hepatitis $\mathrm{C}$ testing and linkage-to-care program at the local public health level. Public Health Rep. 2016;131(Suppl 2):57-64. https://doi.org/10.1177/ 00333549161310s210.

17. Jayasekera CR, Arora S, Ahmed A. Hepatitis C treatment delivery mandates optimizing available health care human resources: a case for task shifting. JAMA. 2016;315(18):1947-8. https://doi.org/10.1001/jama. 2016.1993

This brief viewpoint provides a poignant overview of the need for and data to support task-shifting to impact the HCV epidemic on a global scale.

18. Lasser KE, Heinz A, Battisti L, Akoumianakis A, Truong $\mathrm{V}$, Tsui J, et al. A hepatitis $\mathrm{C}$ treatment program based in a safety-net hospital patient-centered medical home. Ann Fam Med. 2017;15(3):258-61. https://doi.org/10. 1370/afm.2069.

19. Sokol R, Early J, Barner A, Gottfried S, Gumpert R, Libaridian L et al. Implementation of a multidisciplinary, team-based model to treat chronic hepatitis $\mathrm{C}$ in the primary care setting: lessons learned. Healthcare (Amsterdam, Netherlands). 2017. https://doi.org/10. 1016/j.hjdsi.2017.09.005.

20. Islam MM, Topp L, Conigrave KM, White A, Reid SE, Grummett S, et al. Linkage into specialist hepatitis C treatment services of injecting drug users attending a needle syringe program-based primary healthcare centre. J Subst Abus Treat. 2012;43(4):440-5. https://doi. org/10.1016/j.jsat.2012.07.007.

21. Stein MR, Soloway IJ, Jefferson KS, Roose RJ, Arnsten $\mathrm{JH}$, Litwin AH. Concurrent group treatment for hepatitis C: implementation and outcomes in a methadone maintenance treatment program. J Subst Abus Treat. 2012;43(4):424-32.

22.•• Bruggmann P, Litwin AH. Models of care for the management of hepatitis $\mathrm{C}$ virus among people who inject drugs: one size does not fit all. Clin Infect Dis. 2013;57(2):S56-6.

In a growing injection drug use population, this review demonstrates innovative and effective care models for those who inject drugs to receive optimal HCV treatment. 
23. Rattay T, Dumont IP, Heinzow HS, Hutton DW. Cost-effectiveness of access expansion to treatment of hepatitis $C$ virus infection through primary care providers. Gastroenterology. 2017;153(6):1531-1543.e2. https://doi.org/10. 1053/j.gastro.2017.10.016.

24. Mehta DMJ, Gonzalez YS, Marx S, Saab S. Role of physician specialties to close gaps in the care cascade of hepatitis C: evidence from paid claims in the United States from 2010 to 2016. EASL; 2018 April 11-15; Paris, France.

25. Thomson M, Konerman MA, Choxi H, Lok AS. Primary care physician perspectives on hepatitis $C$ management in the era of direct-acting antiviral therapy. Dig Dis Sci. 2016;61(12):3460-8. https://doi.org/10.1007/ s10620-016-4097-2.

26. Washington Uo, Alabama Uo. Hepatitis C online. 2018. https://www.hepatitisc.uw.edu/. Accessed 23 May 2018.

27. Scott JD, Unruh KT, Catlin MC, Merrill JO, Tauben DJ, Rosenblatt R, et al. Project ECHO: a model for complex, chronic care in the Pacific northwest region of the United States. J Telemed Telecare. 2012;18(8):481-4. https://doi.org/10.1258/jtt.2012.gth113.

28. Yoo ER, Perumpail RB, Cholankeril G, Jayasekera CR, Ahmed A. The role of e-health in optimizing taskshifting in the delivery of antiviral therapy for chronic hepatitis C. Telemed J E Health. 2017;23(10):870-3. https://doi.org/10.1089/tmj.2016.0189.

29.• Belperio PS, Chartier M, Ross DB, Alaigh P, Shulkin D. Curing hepatitis $\mathrm{C}$ virus infection: best practices from the U.S. Department of Veterans Affairs. Ann Intern Med. 2017;167(7):499-504. https://doi.org/10.7326/ M17-1073

The Department of Veterans Affairs (VA) has successfully treated more than 92,000 HCV-infected veterans with interferonfree agents. This articles describes key factors related to care delivery that have contributed to large-scale HCV elimination within the VA.

30. Parmar P, Mackie D, Varghese S, Cooper C. Use of telemedicine technologies in the management of infectious diseases: a review. Clin Infect Dis. 2015;60(7):1084-94. https://doi.org/10.1093/cid/ ciu1143.

31. Rossaro L, Aoki C, Yuk J, Prosser C, Goforth J, Martinez F. The evaluation of patients with hepatitis $C$ living in rural California via telemedicine. Telemed J E Health. 2008;14(10):1127-9. https://doi.org/10.1089/tmj. 2008.0029.

32. Dorsey ER, Topol EJ. State of telehealth. N Engl J Med. 2016;375(2):154-61. https://doi.org/10.1056/ NEJMra1601705.

33. Hepatitis C. The state of Medicaid access.. NVHR/Center for Health Law \& Policy Innovation Harvard Law School. 2016. http://nvhr.org/sites/default/files/.users/ u33/HCV\%20Report\%20Card\%20National\% 20Summary_FINAL.pdf. Accessed May 12018 This collaborative effort to expose HCV treatment restrictions for Medicaid patients is frequently updated and useful for providers who work with this population.
34. Clough B, Afdhal N, Milligan S, Slotnik J. TRIOHealth real-world evidence: hepatitis $\mathrm{C}$ treatment demand \& non-starts. http://www.natap.org/2017/ HCV/TrioHealthTroutGroupHepC.PD: TRIOHealth2017.

35. Hepatitis C. Second generation antivirals prior authorization-through preferred agent(s) criteria program summary. Blue Cross Blue Shield of Alabama https:// providers.bcbsal.org/portal/documents/10226/ 299839/Hepatitis+C+Second+Generation+Antivirals+ Prior+Authorization+--Through+Preferred+Agent $\%$ $28 \mathrm{~s} \% 29+$ Criteria+Program+Summary/d8a2c3112c38-47d9-987a-0c30e2ee7082? version=1.12. Accessed 22 May 2018.

36. Prior Authorization/Medical Necessity: Harvoni (sofosbuvir/ledipasvir). United Healthcare, Minneapolis, MN. 2018. https://www.uhcprovider.com/ content/dam/provider/docs/public/prior-auth/drugspharmacy/PA-Med-Nec-Harvoni.pdf. Accessed 22 May 2018.

37. Lo Re V 3rd, Gowda C, Urick PN, Halladay JT, Binkley A, Carbonari DM, et al. Disparities in absolute denial of modern hepatitis $\mathrm{C}$ therapy by type of insurance. Clin Gastroenterol Hepatol. 2016;14(7):1035-43. https://doi. org/10.1016/j.cgh.2016.03.040

This prospective cohort study reports revealing data on HCV treatment approval rates and reasons for denial by insurance type.

38. Trooskin SB, Poceta J, Towey CM, Yolken A, Rose JS, Luqman NL, et al. Results from a geographically focused, community-based HCV screening, linkage-tocare and patient navigation program. J Gen Intern Med. 2015;30(7):950-7. https://doi.org/10.1007/s11606015-3209-6.

39. Vu TM, Toribio W, Riazi F, Ciprian G, Gibbs N, Giardina $M$, et al. Increasing access to hepatitis $C$ virus medications: a program model using patient navigators and specialty pharmacy to obtain prior authorization approval. J Manag Care Spec Pharm. 2018;24(4):329-33. https://doi.org/10.18553/jmcp. 2018.24.4.329.

40. Saab S, Jimenez M, Fong T, Wu C, Bau S, Jamal Z, et al. Accessibility to oral antiviral therapy for patients with chronic hepatitis $\mathrm{C}$ in the United States. J Clin Transl Hepatol. 2016;4(2):76-82. https://doi.org/10.14218/ JCTH.2016.00011.

41. Younossi ZM, Bacon BR, Dieterich DT, Flamm SL, Kowdley K, Milligan S, et al. Disparate access to treatment regimens in chronic hepatitis $\mathrm{C}$ patients: data from the TRIO network. J Viral Hepat. 2016;23(6):447-54. https:// doi.org/10.1111/jvh.12506

This retrospective observational study provides some of the largest data to date on rates and reasons patients do not start DAA therapy after a prescription.

42. Do A, Mittal Y, Liapakis A, Cohen E, Chau H, Bertuccio C, et al. Drug authorization for Sofosbuvir/Ledipasvir (Harvoni) for chronic HCV infection in a real-world cohort: a new barrier in the HCV care cascade. PLoS One. 2015;10(8):e0135645. https://doi.org/10.1371/ journal.pone.0135645. 
43. Dunn EE, Vranek K, Hynicka LM, Gripshover J, Potosky D, Mattingly TJ. Evaluating a collaborative approach to improve prior authorization efficiency in the treatment of hepatitis C virus. Qual Manag Health Care. 2017;26(3):136-9. https://doi.org/10.1097/QMH. 0000000000000137.

44. Bagwell A, Kelley T, Carver A, Lee JB, Newman B. Advancing patient care through specialty pharmacy Services in an Academic Health System. J Manag Care Spec Pharm. 2017;23(8):815-20. https://doi.org/10. 18553/jmcp.2017.23.8.815.

45. Zhu J, Hazen RJ, Joyce C, Delpino A, Kirkham HS, Strickland CD et al. Local specialty pharmacy and specialty clinic collaboration assists access to hepatitis C direct-acting antivirals. J Am Pharm Assoc. 2003;2017. https://doi.org/10.1016/j.japh.2017.10.011.

46. Association/IDSA HM. HCV treatment access: appeals \& patient assistance. HIV Medicine Association/IDSA, Arlington, VA. http://hcvtreatmentaccess.org/drugappeals/\#section2. Accessed 2 June 2018.

47. Provider Resources. National Viral Hepatitis Roundtable (NVHR). http://nvhr.org/content/providerresources. Accessed 2 May 2018.

48. AASLD-IDSA. Monitoring patients who are starting HCV treatment, are on treatment, or have completed therapy. American Association for the Study of Liver Diseases and the Infectious Diseases Society of America. 2018. https:// www.hcvguidelines.org/evaluate/monitoring. Accessed 2 June 2018.

The AASLD-IDSA HCV Guidance provides recommendations for testing, managing, and treating HCV and is regularly reviewed and updated. This section discusses monitoring patient before, during, and after HCV treatment.

49. Liverpool Uo. Hep drug interactions. The University of Liverpool. 2016. http://www.hep-druginteractions. org/checker. Accessed July 30th 2016.

This provider tool, endorsed by AASLD/IDSA Guidance, is useful for to help HCV treatment prescribers identify, measure, and mitigate possible drug interactions with DAA therapy.

50. Levin JM, Dabirshahsahebi S, Bauer M, Huckins E. Retrospective analysis of hepatitis $\mathrm{C}$ infected patients treated through an integrated care model. World J Gastroenterol. 2016;22(38):8558-67. https://doi.org/ 10.3748/wig.v22.i38.8558.

51. Zaepfel M, Cristofaro L, Trawinski A, McCarthy K, Rightmier E, Khadem T. Evaluation of a hepatitis C patient management program at a university specialty pharmacy. Ann Pharmacother. 2017;51(4):307-14. https://doi.org/10.1177/1060028016683495.

52. Chamorro-de-Vega E, Rodriguez-Gonzalez CG, Gimenez-Manzorro A, de Lorenzo-Pinto A, IglesiasPeinado I, Herranz A, et al. Improving pharmacotherapy outcomes in patients with hepatitis $\mathrm{C}$ virus infection treated with direct-acting antivirals: the GRUviC project. Int J Clin Pract. 2017;71(8). https://doi.org/10. 1111/ijcp.12988.

53. Bagwell A, Douglas A, Chastain C. Evaluation of the hepatitis $C$ cascade of care in a multidisciplinary infectious diseases clinic. Open Forum Infectious
Diseases. 2017;4(suppl_1):S200-S. https://doi.org/10. 1093/ofid/ofx163.385.

54. Cooper CL, Hatashita H, Corsi DJ, Parmar P, Corrin R, Garber G. Direct-acting antiviral therapy outcomes in Canadian chronic hepatitis $\mathrm{C}$ telemedicine patients. Ann Hepatol. 2017;16(6):874-80. https://doi.org/10. 5604/01.3001.0010.5277.

55. Rossaro L, Torruellas C, Dhaliwal S, Botros J, Clark G, Li CS, et al. Clinical outcomes of hepatitis C treated with pegylated interferon and ribavirin via telemedicine consultation in northern California. Dig Dis Sci. 2013;58(12):3620-5. https://doi.org/10.1007/ s10620-013-2810-y.

56. Nazareth S, Kontorinis N, Muwanwella N, Hamilton A, Leembruggen N, Cheng WS. Successful treatment of patients with hepatitis $\mathrm{C}$ in rural and remote Western Australia via telehealth. J Telemed Telecare. 2013;19(2):101-6. https://doi.org/10.1258/jtt.2012. 120612.

57. Sims OT, Melton PA, Ji S. A descriptive analysis of a community clinic providing hepatitis $\mathrm{C}$ treatment to poor and uninsured patients. J Community Health. 2018;43:725-30. https://doi.org/10.1007/s10900018-0476-2.

58. Sublette VA, Hopwood M, George J, Smith SK, Perry $\mathrm{KN}$, McCaffery K, et al. Instrumental support to facilitate hepatitis $\mathrm{C}$ treatment adherence: working around shortfalls in shared-care. Psychol Health Med. 2015;20(2):186-97. https://doi.org/10.1080/ 13548506.2014.933852.

59. Schutz A, Moser S, Schwanke C, Schubert R, Luhn J, Gutic E et al. Directly observed therapy of chronic hepatitis $\mathrm{C}$ with ledipasvir/sofosbuvir in people who inject drugs at risk of nonadherence to direct-acting antivirals. J Viral Hepat. 2018. https://doi.org/10.1111/ jvh.12857.

This open-label proof-of-concept study describes successful HCV treatment of injection drug users provided in tangent with opioid agonist therapy. All patients achieved a clinical cure of HCV.

60. AASLD-IDSA. Recommendations for testing, managing, and treating hepatitis C. http://www. hcvguidelines.org. Accessed 17 June 2018.

The AASLD-IDSA HCV Guidance provides recommendations for testing, managing, and treating HCV and is regularly reviewed and updated.

61. Simmons B, Saleem J, Hill A, Riley RD, Cooke GS. Risk of late relapse or reinfection with hepatitis $C$ virus after achieving a sustained virological response: a systematic review and meta-analysis. Clin Infect Dis.

2016;62(6):683-94. https://doi.org/10.1093/cid/civ948 This study examined reinfection risk delineated by risk category through search and analysis of previously published literature.

62. Weir A, McLeod A, Innes H, Valerio H, Aspinall EJ, Goldberg DJ, et al. Hepatitis C reinfection following treatment induced viral clearance among people who have injected drugs. Drug Alcohol Depend. 2016;165:53-60. https://doi.org/10.1016/j. drugalcdep.2016.05.012. 
63. Ingiliz P, Martin TC, Rodger A, Stellbrink HJ, Mauss S, Boesecke $\mathrm{C}$, et al. HCV reinfection incidence and spontaneous clearance rates in HIV-positive men who have sex with men in Western Europe. J Hepatol. 2017;66(2):282-7. https://doi.org/10.1016/j.jhep. 2016.09.004.
64. Martinello M, Grebely J, Petoumenos K, Gane E, Hellard M, Shaw D, et al. HCV reinfection incidence among individuals treated for recent infection. J Viral Hepat. 2017;24(5):359-70. https://doi.org/10.1111/ jvh.12666. 